\title{
New Two-Dimensional Polynomial Failure Criteria for Composite Materials
}

\author{
Shi Yang Zhao and Pu Xue \\ School of Aeronautics, Northwestern Polytechnical University, Xian 710072, China \\ Correspondence should be addressed to Shi Yang Zhao; haiyangrongyang@sina.com
}

Received 6 March 2014; Revised 27 April 2014; Accepted 28 April 2014; Published 28 May 2014

Academic Editor: Gonzalo Martínez-Barrera

Copyright (c) 2014 S. Y. Zhao and P. Xue. This is an open access article distributed under the Creative Commons Attribution License, which permits unrestricted use, distribution, and reproduction in any medium, provided the original work is properly cited.

\begin{abstract}
The in-plane damage behavior and material properties of the composite material are very complex. At present, a large number of two-dimensional failure criteria, such as Chang-Chang criteria, have been proposed to predict the damage process of composite structures under loading. However, there is still no good criterion to realize it with both enough accuracy and computational performance. All these criteria cannot be adjusted by experimental data. Therefore, any special properties of composite material cannot be considered by these criteria. Here, in order to solve the problem that the criteria cannot be adjusted by experiment, new two-dimensional polynomial failure criteria with four internal parameters for composite laminates are proposed in the paper, which include four distinct failure modes: fiber tensile failure, fiber compressive failure, matrix tensile failure, and matrix compressive failure. In general, the four internal parameters should be determined by experiments. One example that identifies parameters of the new failure criteria is given. Using the new criteria can reduce the artificialness of choosing the criteria for the damage simulation of the failure modes in composite laminates.
\end{abstract}

\section{Introduction}

Fiber-reinforced polymer (FRP) composites are widely applied in aerospace, marine, and many other industries due to their lightweight, high stiffness, strength, and damping properties [1]. In order to get strong and reliable structures, it is very important to study the mechanical behavior of FRP. In the studies, the finite element method is proved to be effective and successful which can predict the behavior of composite structures under various loading conditions. From the literatures, many researches can be found on the behavior of composites, such as buckling loads, modal characteristics, damage, and failure. Zhang and Yang [2] gave comprehensive reviews and some of the future research on composite laminated plates. Orifici et al. [3] also gave a critical review to assess the state of the art in material constitutive modeling and composite failure theories. They summarized the various theories and approaches within the context of the dissipated energy framework. The dissipated energy function, with units of energy per unit volume, could be determined from experimental testing and was postulated to be a property of the material. Based on the continuum damage mechanics (CDM), Liu and Zheng [4] reviewed the damage constitutive modeling, the failure criteria, and the finite element implementation in the progressive failure analysis which predicted the stiffness degradation and failure strengths of composite laminates. Specially, the methodologies to solve the numerical convergence problems due to the loss of element stiffness in the finite element analysis were discussed.

The failure behavior and damage analysis of the composite laminated structures by the finite element method are paid the most attention by researchers. Michopoulos's work [5] shows that there is a relationship among many criteria. Hinton et al. [6-11] listed 19 theories of failure criteria proposed for composite laminates and gave a comparison of their predictive capabilities. They showed similarities and differences between the predictions of the 19 theories by comparing the initial and final failure envelopes and representative stress-strain curves. They also explained the 
differences between the predictions. They did not intend to prove which theory is the best but just clarified their differences between their predictions.

Despite a large number of published papers on the damage and failure behavior of the composite laminates under various loadings, a very effective criterion to predict the failure behavior of composites has not achieved yet. Several widely used phenomenological failure criteria, such as the maximum stress, Hoffman, Tsai-Wu, and TsaiHill failure criteria $[8,11-14]$, are proposed to describe the whole ply failure of composite material structures. Other popular phenomenological failure criteria, such as Hashin criteria, Hou criteria, Chang-Chang criteria, Linde criteria, LaRC0 4 criteria, and Maimí criteria [15-21], can describe the damage process of composite structures in detail, such as fiber breakage, fiber buckling, matrix cracking, therefore, matrix compression. All these criteria cannot be adjusted by experiments. Therefore, any special properties of composite material cannot be considered by these criteria. By studying the problems of dynamic bending failure of composite laminated beams, Santiuste et al. [22] suggested that Hashin criteria may be suitable for ductile composite material, and Hou criteria may be suitable for brittle material in unidirectional laminated beams. Therefore, for different material and different structures, just one failure criterion which cannot be adjusted by experiments could not satisfy various requirements.

When we use some known criteria in our study directly, it has used a supposition that material properties used in your own engineering are the same as that in the study which proposed the known criteria. In fact, the failure criteria should be decided by experiments. If one criterion is decided by experiments, the criterion can consider special properties of any material used in engineering. And also, you can use the new failure criteria in numerical simulation to get better numerical results. Here we try to propose new two-dimensional polynomial failure criteria, which can be adjusted by experiments.

New two-dimensional polynomial failure criteria with four internal parameters for composite laminates are proposed in the paper. Four distinct failure modes including fiber tensile failure, fiber compressive failure, matrix tensile failure, and matrix compressive failure are considered in the extended criteria. Meanwhile, when some special values are given to the four internal parameters, the extended criteria will become some classical failure criteria such as ChangChang criteria, Hashin criteria, and Hou criteria in two dimensional case. Finally, the features of the failure criteria are discussed in detail. And one example that chooses proper values for the parameters in the criteria is given.

\section{New Two-Dimensional Failure Criteria}

The damage of composite laminates under loading includes intraply failure and interply failure [23]. Intraply failure modes are fiber kinking, fiber fracture, matrix cracking, and matrix-fiber debonding. Interply failure modes are interface cracks between plies.
New two-dimensional polynomial failure criteria for composite laminates are with four internal parameters. And each failure mode has a parameter. Therefore, four failure modes all can be adjusted by experiments. And almost special properties of each failure mode can be considered. New two-dimensional polynomial failure criteria are obtained by comparing common and characteristic parts of the present failure criteria, such as Chang-Chang criteria, Hou Criteria, Hashin criteria, and Linde criteria.

2.1. Definition of Variables. The related variables include stress components, $\sigma_{1}, \sigma_{2}, \sigma_{12}$; the tensile damage variable of fiber, $d_{f t}$; the compressive damage variable of fiber, $d_{f_{c}}$; the tensile damage variable of matrix, $d_{m t}$; the compressive damage variable of matrix, $d_{m c}$; some material properties: longitudinal failure stress strength, $X_{T}, X_{C}$; transverse failure stress strength, $Y_{T}, Y_{c}$; in-plane shear failure stress strength, $S_{12}$; the subscripts " $T$ " and " $C$ " refer to tension and compression.

2.2. Fiber Tensile Failure. Under tension loading, fiber is the main portion to carry load. In composites with high fiber volume fraction and those whose failure strain of the matrix is higher than that of the reinforcing fiber, such as carbonepoxy composites, longitudinal failures start by isolated fiber fractures in weak zones [20]. The localized fractures increase the normal and interfacial shear stresses in adjoining fiber, and the local stress concentration promotes matrix cracking and fiber and matrix debonding [24].

Fiber failure criteria in tension are the most simple damage form for composite laminates. After the accumulation of fracture energy, individual fiber will fail until that the whole ply failure happens. And the whole laminates will carry any loads. In general, the maximum stress strength or strain strength is used to predict fiber failure.

A new fiber failure criterion in tensile is

$$
\begin{aligned}
d_{f t}= & k_{1} *\left(\frac{\sigma_{1}}{X_{T}}\right)^{2}+\left(1-k_{1}\right) * \frac{\sigma_{1}}{X_{T}} \\
& +\beta_{1} \frac{\sigma_{12}^{2} / 2 G_{12}+3 / 4 \alpha \sigma_{12}^{4}}{S_{12}^{2} / 2 G_{12}+3 / 4 \alpha S_{12}^{4}} \geq 1, \quad \sigma_{1} \geq 0,
\end{aligned}
$$

where $k_{1}$ is a parameter of the criteria of fiber failure; $\beta_{1}$ is used to consider the interaction form involving in-plane shear, which can take two values: 0 or $1 ; \alpha$ is a parameter for the shear nonlinear effect, which can take two values: 0 or 1 .

2.3. Fiber Compressive Failure. Under fiber compression loads, laminate failure modes are complex and depend on the material properties. The modes may be microbucking, kinking, and fiber failure $[25,26]$. The structures may be in the state of collapse.

The criteria for fiber compressive failure are almost the same as the fiber tensile failure, although the failure phenomenon of fiber compressive failure is more complex than the fiber tensile failure. 
A new fiber failure criterion in compression is

$$
\begin{gathered}
d_{f c}=k_{2} *\left(\frac{\sigma_{1}}{X_{c}}\right)^{2}+\gamma *\left(k_{2}-1\right) * \frac{\sigma_{1}}{X_{c}} \\
+\beta_{2} *\left(\frac{\sigma_{12}}{S}\right)^{2} \geq 1, \quad \sigma_{1} \leq 0,
\end{gathered}
$$

where $k_{2}$ is a parameter; $\beta_{2}$ is used to consider the interaction form involving in-plane shear, which can take two values: 0 or $1 ; \gamma$ is a parameter which can take two values: 1 and 0 .

2.4. Failure Criteria for Matrix. Under transverse loading, the behavior of the material is more complex than the fiber failure. A nonlinear stress-strain response will be observed if the laminate is loaded in the transverse direction or in the shear direction. The famous Chang-Chang failure criteria considered the nonlinear shear effects and introduced a coefficient to characterize the nonlinearity. The nonlinear constitutive relation proposed by Richard and Blacklock [27] introduced an exponential degradation form. In general, the fracture plane is perpendicular to the mid-plane of the ply under transverse tensile load. But the angle of the fracture plane will change if transverse stress increases under the compressive load. Generally, for carbon-epoxy and glassepoxy composites loaded in pure transverse compression, the fracture plane is at an angle of $53^{\circ} \pm 3^{\circ}$ with respect to the thickness direction $[20,28]$. The LaRC0 4 criteria consider the alterative influence of the angle. However, the computational efficiency decreases if the fracture angle changes frequently, so Maimí et al. assumed that the fracture angle can only take one of the two discrete values: $0^{\circ}$ or $53^{\circ}$ [20].

Here, two-dimensional matrix failure criteria for composite materials are expressed by a quadratic polynomial. They will also not include the variable of the mutative fractural angle.

2.4.1. Matrix Tensile Failure. The criteria for matrix tensile failure involve an interaction between the tensile normal and in-plane shear stresses.

A new matrix failure criterion in tension is

$$
\begin{array}{r}
d_{m t}=k_{3}\left(\frac{\sigma_{2}}{Y_{T}}\right)^{2}+\left(1-k_{3}\right) \frac{\sigma_{2}}{Y_{T}}+\frac{\sigma_{12}^{2} / 2 G_{12}+3 / 4 \alpha \sigma_{12}^{4}}{S_{12}^{2} / 2 G_{12}+3 / 4 \alpha S_{12}^{4}} \\
\sigma_{2} \geq 0
\end{array}
$$

where $k_{3}$ is a parameter; $\alpha$ is used to consider the nonlinear interaction form involving in-plane shear.

2.4.2. Matrix Compressive Failure. The criteria for matrix tensile failure are complex in Hashin criteria, Hou criteria, and Chang-Chang criteria. The coefficients of quadratic polynomials are different. Therefore, it is advisable to define the matrix failure criterion in compression with parameters. Parameters should be chosen by experiments.
A new matrix failure criterion in tension is as follows:

$$
\begin{array}{r}
d_{m c}=k_{4}\left(\frac{\sigma_{2}}{Y_{c}}\right)^{2}+\left(k_{4}-1\right) \frac{\sigma_{2}}{Y_{c}}+\frac{\sigma_{12}^{2} / 2 G_{12}+3 / 4 \alpha \sigma_{12}^{4}}{S_{12}^{2} / 2 G_{12}+3 / 4 \alpha S_{12}^{4}}, \\
\sigma_{2} \leq 0,
\end{array}
$$

where $k_{4}$ is a parameter; $\alpha$ is used to consider the nonlinear interaction form involving in-plane shear.

So far, the two-dimensional failure criteria for composite materials are given.

\section{Features of the New Criteria}

3.1. Unified Expression of Fiber and Matrix Failure Criteria. The new failure criteria for primary damage failure behavior are given above. In fact, the new criteria can be rewritten as a tensor form as follows:

$$
\begin{aligned}
d_{i l}= & k_{i} *\left(\frac{\sigma_{i}}{X_{i l}}\right)^{2}+\gamma_{i} *(1-k) *\left|\frac{\sigma_{i}}{X_{i l}}\right| \\
& +\beta_{i} *\left(\frac{\sigma_{12}^{2} / 2 G_{12}+3 / 4 \alpha_{i} \sigma_{12}^{4}}{S_{12}^{2} / 2 G_{12}+3 / 4 \alpha_{i} S_{12}^{4}}\right)^{2} \geq 1,
\end{aligned}
$$

where $k_{i}$ is a parameter; $\beta_{i}$ is used to consider the interaction form involving in-plane shear; $\gamma_{i}$ is a parameter which can take two values: 1 and $0 ; \|$ is the sign of the absolute value; $i$ is used to denote the damage category: fiber or matrix; $l$ is for the stress direction: tensile or compression.

3.2. Some Special Forms of the New Criteria. In fact, ChangChang criteria, Hou criteria, and so forth are proposed from some special materials, such as carbon/epoxy and graphite epoxy. Therefore, the validity of parameters in these criteria is very limited. All these known criteria are just good at simulating some special material. If more accurate numerical results are needed, the failure criteria of every material should consider their own material properties and be given one set of special values of parameters. And all these parameters are from experiments. When some special values got by experiments are given to four parameters of the new criteria, it will get good numerical results. Meanwhile, when some special values are given to the four internal parameters, the new criteria will become these classical failure criteria such as Chang-Chang criteria, Linde criteria, Hashin criteria, and Hou criteria in two dimensional case.

When $k_{1}=1, \beta_{1}=1, \alpha=0 ; k_{2}=1, \beta_{2}=0, \gamma=0 ; k_{3}=1$; $k_{4}=\left(Y_{c} / 2 / S_{23}\right)^{2}$, the new criteria will become Hashin criteria in two-dimensional case as follows:

$$
\begin{gathered}
d_{f t}=\left(\frac{\sigma_{1}}{X_{T}}\right)^{2}+\left(\frac{\sigma_{12}}{S}\right)^{2} \geq 1, \quad \sigma_{1} \geq 0 \\
d_{f c}=\left(\frac{\sigma_{1}}{X_{c}}\right)^{2} \geq 1, \quad \sigma_{1} \leq 0
\end{gathered}
$$




$$
\begin{gathered}
d_{m t}=\left(\frac{\sigma_{22}}{Y_{T}}\right)^{2}+\left(\frac{\sigma_{12}}{S_{12}}\right)^{2}, \quad \sigma_{22} \geq 0 \\
d_{m c}=\left(\frac{Y_{c}}{2 S_{23}}\right)^{2}\left(\frac{\sigma_{22}}{Y_{c}}\right)^{2}+\left[\left(\frac{Y_{c}}{2 S_{23}}\right)^{2}-1\right] \frac{\sigma_{22}}{Y_{c}} \\
+\left(\frac{\sigma_{12}}{S_{12}}\right)^{2} \geq 1, \quad \sigma_{22}<0 .
\end{gathered}
$$

When $k_{1}=1, \beta_{1}=1, \alpha=0 ; k_{2}=1, \beta_{2}=1, \gamma=0 ; k_{3}=1 ;$ $k_{4}=\left(Y_{c} / 2 / S_{12}\right)^{2}$, the new criteria will become Hou criteria in two dimensional case as follows:

$$
\begin{gathered}
d_{f t}=1 *\left(\frac{\sigma_{1}}{X_{T}}\right)^{2}+(1-1) * \sigma_{1}+\left(\frac{\sigma_{12}}{S}\right)^{2} \geq 1, \quad \sigma_{1} \geq 0, \\
d_{f c}=\left(\frac{\sigma_{1}}{X_{T}}\right)^{2}+\left(\frac{\sigma_{12}}{S}\right)^{2} \geq 1, \quad \sigma_{1} \leq 0, \\
d_{m t}=\left(\frac{\sigma_{22}}{Y_{T}}\right)^{2}+\left(\frac{\sigma_{12}}{S_{12}}\right)^{2}+\left(\frac{\sigma_{23}}{S_{23}}\right)^{2}, \quad \sigma_{22} \geq 0, \\
d_{m c}=\frac{1}{Y_{c}}\left[\left(\frac{Y_{c}}{2 S_{12}}\right)^{2}-1\right] \sigma_{22}+\frac{\sigma_{22}^{2}}{4 S_{12}^{2}} \\
+\left(\frac{\sigma_{12}}{S_{12}}\right)^{2} \geq 1, \quad \sigma_{22}<0 .
\end{gathered}
$$

When $k_{1}=X_{T} / X_{c}, \beta_{1}=0, \alpha=0 ; k_{2}=X_{c} / X_{T}, \beta_{2}=0$, $\gamma=1 ; k_{3}=Y_{T} / Y_{c} ; k_{4}=Y_{c} / Y_{T}$, the new criteria will become Linde criteria in two dimensional case as follows:

$$
\begin{gathered}
d_{f}=\left(\frac{1}{X_{T}}-\frac{1}{X_{c}}\right) \sigma_{1}+\frac{1}{X_{T} X_{c}} \sigma_{1}^{2}, \\
d_{m}=\left(\frac{1}{Y_{T}}-\frac{1}{Y_{c}}\right) \sigma_{2}+\frac{1}{Y_{T} Y_{c}} \sigma_{2}^{2}+\left(\frac{\sigma_{12}}{S_{12}}\right)^{2} .
\end{gathered}
$$

When $k_{1}=1, \beta_{1}=1, \alpha=1 ; k_{2}=1, \beta_{2}=0, \gamma=0 ; k_{3}=1$; $k_{4}=1$, the new criteria will become Chang-Chang criteria as follows:

$$
\begin{gathered}
d_{f t}=\left(\frac{\sigma_{1}}{X_{T}}\right)^{2}+\frac{\sigma_{12}^{2} / 2 G_{12}+3 / 4 \alpha \sigma_{12}^{4}}{S_{12}^{2} / 2 G_{12}+3 / 4 \alpha S_{12}^{4}} \geq 1, \quad \sigma_{1} \geq 0, \\
d_{f c}=\left(\frac{\sigma_{1}}{X_{c}}\right)^{2} \geq 1, \quad \sigma_{1} \leq 0, \\
d_{m t}=\left(\frac{\sigma_{22}}{Y_{T}}\right)^{2}+\frac{\sigma_{12}^{2} / 2 G_{12}+3 / 4 \alpha \sigma_{12}^{4}}{S_{12}^{2} / 2 G_{12}+3 / 4 \alpha S_{12}^{4}}, \quad \sigma_{22} \geq 0, \\
d_{m c}=\left(\frac{\sigma_{22}}{Y_{c}}\right)^{2}+\frac{\sigma_{12}^{2} / 2 G_{12}+3 / 4 \alpha \sigma_{12}^{4}}{S_{12}^{2} / 2 G_{12}+3 / 4 \alpha S_{12}^{4}}, \quad \sigma_{22} \leq 0 .
\end{gathered}
$$

TABLE 1: Failure strengths of T300/914C.

\begin{tabular}{lcccc}
\hline$X_{T} / \mathrm{Mpa}$ & $X_{\mathrm{C}} / \mathrm{Mpa}$ & $Y_{T} / \mathrm{Mpa}$ & $Y_{\mathrm{C}} / \mathrm{Mpa}$ & $S_{12} / \mathrm{Mpa}$ \\
\hline 1500 & 900 & 27 & 200 & 80 \\
\hline
\end{tabular}

TABLE 2: Failure strengths of E-glass/Ly556/HT907/DY063 epoxy.

\begin{tabular}{cccccc}
\hline$X_{T} / \mathrm{Mpa}$ & $X_{\mathrm{C}} / \mathrm{Mpa}$ & $Y_{T} / \mathrm{Mpa}$ & $Y_{\mathrm{C}} / \mathrm{Mpa}$ & $S_{12} / \mathrm{Mpa}$ & $G_{I} / \mathrm{J} / \mathrm{m}^{2}$ \\
\hline 1500 & 900 & 27 & 200 & 80 & 165 \\
\hline
\end{tabular}

When $k_{3}=G_{I c} / G_{I I c}, \alpha=0$, (3) will be one part of the failure criteria LaR04, shown in (10). $G_{I c}, G_{I I c}$ are the fracture toughness of Mode I and Mode II, respectively,

$$
d_{m t}=\frac{G_{I c}}{G_{I I c}}\left(\frac{\sigma_{2}}{Y_{T}}\right)^{2}+\left(1-\frac{G_{I c}}{G_{I I c}}\right) \frac{\sigma_{2}}{Y_{t}}+\left(\frac{\sigma_{12}}{S_{12}}\right)^{2}, \quad \sigma_{2} \geq 0 .
$$

From (5)-(9), we find that the new criteria with four parameters have enough capability to match the failure criteria which are used widely in the damage analysis of composite materials.

The parameters of the new failure criterion can be defined by experimental data to get better numerical results.

\section{Identifying Parameters of the New Failure Criteria}

The process of identifying parameters of the new failure criteria by experiments is shown here.

Biaxial tests of E-glass and carbon fiber reinforced composite laminates were performed by Soden et al. [29]. In biaxial tests, just $\sigma_{1}, \sigma_{2}$, and $\sigma_{12}$ can be obtained. Therefore, just parameters $k_{1}, k_{2}, k_{3}$, and $k_{4}$ can be identified by experimental data. The other parameters $\beta_{1}, \beta_{2}, \alpha, \gamma$ in the new criteria are not the main items. In fact, $\gamma$ is used to consider the influence of linear item, $\sigma_{1}$, to the fiber tensile damage; $\beta_{1}$ is used to consider the influence of shear stress, $\sigma_{12}$, to the fiber tensile damage; $\beta_{2}$ is used to consider the influence of shear stress, $\sigma_{12}$, to the fiber compressive damage; $\alpha$ is used to consider the influence of nonlinear factor of material. The corresponding real values of the parameters of $\beta_{1}, \beta_{2}, \alpha, \gamma$ in Chang-Chang criteria, Linde criteria, Hashin criteria, and Hou criteria in two dimensional case are almost the same. Therefore, based on the four failure criteria above, the parameters, $\beta_{1}=1, \beta_{2}=1, \alpha=0, \gamma=1$, are assumed. In order to reduce the complexity of identifying parameters, $k_{1}, k_{2}, k_{3}, k_{4}$, we just choose the corresponding coefficients of those parameters from Hashin, Hou, Linde, and ChangChang criteria, such as $k_{1}=1, X_{T} / X_{C} ; k_{2}=1,\left(X_{c} / X_{T}\right)^{2}$ and $X_{c} / X_{T} ; k_{3}=1, Y_{T} / Y_{c}$ and $G_{I c} / G_{I I c} ; k_{4}=\left(Y_{c} / 2 S_{12}\right)^{2}, 1$ or $Y_{c} / Y_{T}$.

4.1. Experiments. E-glass and carbon fiber reinforced composite laminates were used in biaxial tests [29]. Their material properties are listed in Tables 1 and 2, respectively.

Biaxial failure for unidirectional T300/914C carbon/epoxy lamina is expressed under combined longitudinal and 


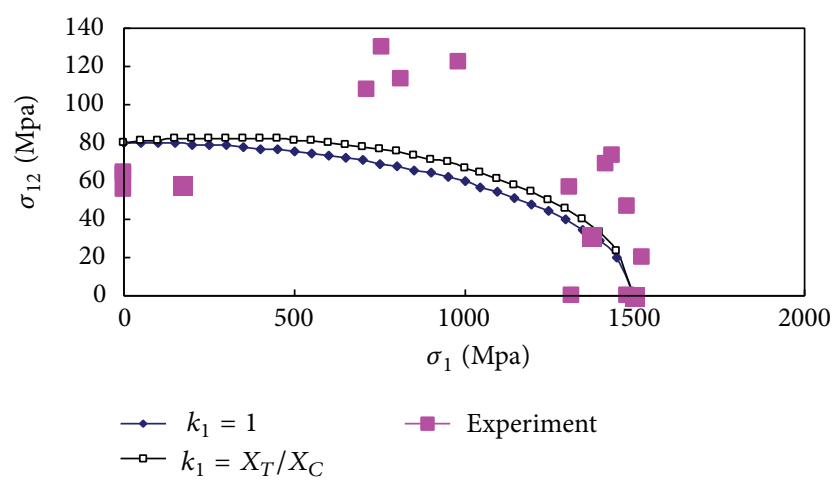

FIgURE 1: Fiber tensile failure envelope.

shear loading $\left(\sigma_{1}\right.$ versus $\left.\sigma_{12}\right)$. The specimens were in the form of axially wound tubes made from prepreg T300/BSL914C carbon/epoxy. The tubes were tested under combined axial tension or compression and torsion. All the tubes were end reinforced and grips were used to transmit the torque to the tubes [29].

Biaxial failure for unidirectional E-glass/Ly556/HT907/ DY063 epoxy lamina is expressed under combined transverse and shear loading ( $\sigma_{2}$ versus $\left.\sigma_{12}\right)$. The tubes with filament wound by circumferentially wound were $60 \mathrm{~mm}$ in internal diameter and $2 \mathrm{~mm}$ in thickness and were constructed from $62 \%$ by volume Vetrotes $21 * \mathrm{~K} 43 \mathrm{E}$-glass fiber (Gevetex) rovings and a Ciba-Geigy epoxy resin system Ly556/HT907/DY063 mixed in weight proportions of $100: 85: 4$. The tubes were cured at $100^{\circ} \mathrm{C}$ for $2 \mathrm{~h}$ and postcurved at $150^{\circ} \mathrm{C}$ for $2 \mathrm{~h}$ [29].

4.2. Determination of Parameters. The parameters, $\beta_{1}=1$, $\beta_{2}=1, \alpha=0, \gamma=1$, are assumed, which are based on Chang-Chang criteria, Linde criteria, Hashin criteria, and Hou criteria in two dimensional case. And (1)-(4) of the new criteria should be rewritten as follows.

\subsubsection{For Fiber Tensile Failure. Consider}

$d_{f t}=k_{1} *\left(\frac{\sigma_{1}}{X_{T}}\right)^{2}+\left(1-k_{1}\right) * \frac{\sigma_{1}}{X_{T}}+\left(\frac{\sigma_{12}}{S_{12}}\right) \geq 1, \quad \sigma_{1} \geq 0$,

where $k_{1}$ is a parameter which can take two values: 1 and $X_{T} / X_{C}$. The curves of (11) are shown in Figure 1. The curve of $k_{1}=1$ and the curve of $k_{1}=X_{T} / X_{C}$ are both lying between the experimental data, which are both effective. However, the curve of $k_{1}=X_{T} / X_{C}$ is close to a large number of experimental data above in Figure 1. Therefore, the curve of $k_{1}=X_{T} / X_{C}$ is used for failure analysis of T300/914C carbon/epoxy lamina.

\subsubsection{For Fiber Compressive Failure. Consider}

$$
d_{f c}=k_{2} *\left(\frac{\sigma_{1}}{X_{c}}\right)^{2}+\left(k_{2}-1\right) * \frac{\sigma_{1}}{X_{c}}+\left(\frac{\sigma_{12}}{S_{12}}\right) \geq 1, \quad \sigma_{1} \leq 0,
$$

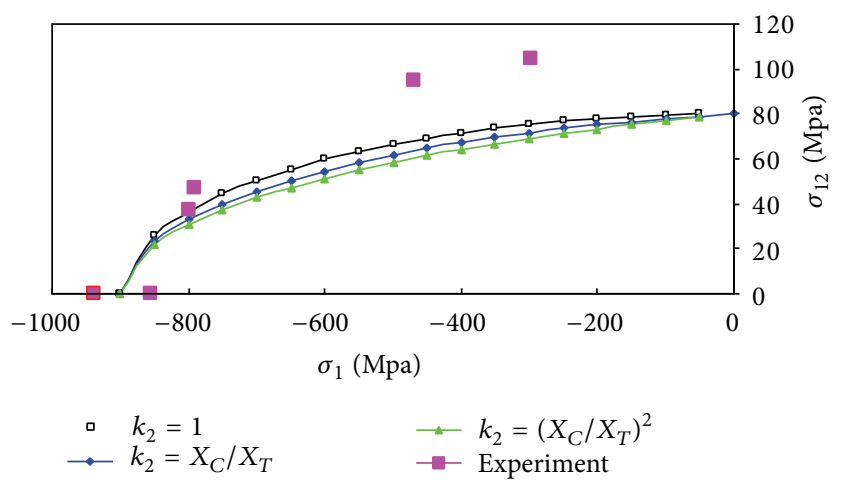

FIgURE 2: Fiber compressive failure envelope.

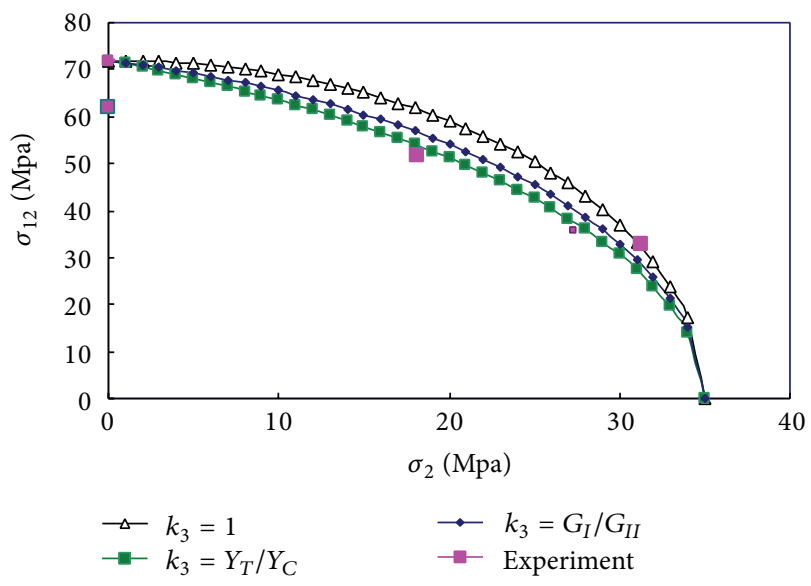

Figure 3: Matrix tensile failure envelope.

where $k_{2}$ is a parameter which can take three values: 1 , $\left(X_{c} / X_{T}\right)^{2}$, and $X_{c} / X_{T}$. The curves of (12) are shown in Figure 2. The curve of $k_{2}=1$ is outmost among all curves in Figure 2, and the experimental data is almost out of the envelope of all curves. The difference of the curve of $k_{2}=1$ with the data is minimal. Therefore, the value $k_{2}=1$ should be used for failure analysis of T300/914C carbon/epoxy lamina.

\subsubsection{For Matrix Tensile Failure. Consider}

$$
d_{m t}=k_{3} *\left(\frac{\sigma_{22}}{Y_{T}}\right)^{2}+\left(1-k_{3}\right) * \sigma_{22}+\left(\frac{\sigma_{12}}{S_{12}}\right)^{2}, \quad \sigma_{22} \geq 0,
$$

where $k_{3}$ is a parameter which can take three values: $1, Y_{T} / Y_{c}$, and $G_{I c} / G_{I I c}$. The curves of (13) are shown in Figure 3. The number of the experimental data is just five. The curve of $k_{3}=$ $Y_{T} / Y_{C}$ is nethermost. Three data are just in the curve of $k_{3}=$ $Y_{T} / Y_{C}$, and the difference of the curve $k_{3}=Y_{T} / Y_{C}$ is minimal. Therefore, the value $k_{3}=Y_{T} / Y_{C}$ should be used for failure analysis of E-glass/Ly556/HT907/DY063 epoxy lamina. 


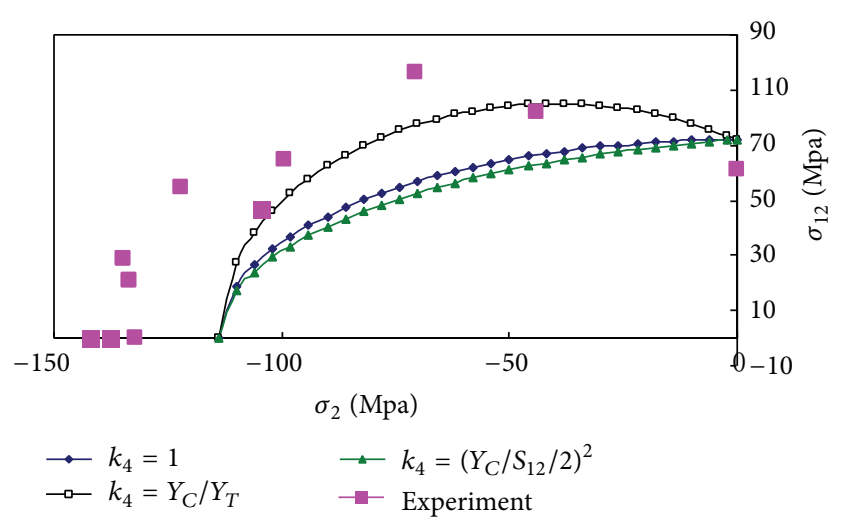

FIGURE 4: Matrix compressive failure envelope.

4.2.4. For Matrix Compressive Failure. Consider

$$
d_{m c}=k_{4}\left(\frac{\sigma_{22}}{Y_{c}}\right)^{2}+\left(k_{4}-1\right) \frac{\sigma_{22}}{Y_{c}}+\left(\frac{\sigma_{12}}{S_{12}}\right)^{2} \geq 1, \quad \sigma_{22}<0,
$$

where $k_{4}$ is a parameter which can take three values: $\left(Y_{c} / 2 S_{12}\right)^{2}, 1$, or $Y_{c} / Y_{T}$. The curves of (14) are shown in Figure 4. Because of the difference between the strength obtained through experiments and that used in material property, three curves are all not perfect. From Figure 4, the curve of $k_{4}=Y_{c} / Y_{T}$ is close to experimental data. Therefore, the value of $k_{4}=Y_{c} / Y_{T}$ should be used in failure analysis of E-glass/Ly556/HT907/DY063 epoxy lamina.

From the discussion above, it is found that it is not enough for the damage criterion that has only one set of the parameters. The failure criteria should be adjusted by experimental data for the materials to meet higher accurate requirement.

\section{Conclusions}

In this work, new two-dimensional failure criteria with four parameters for composite materials are given. The new criteria include fiber failure criteria in tension and compression and matrix failure criteria in tension and compression.

The new criteria can be adjusted with four parameters to consider different material properties in engineering. In general, when we use some known criteria in our study, it has to assume that our material properties are the same as that in the study which proposed the known criteria. Those problems above can be solved by the new criteria proposed in this paper. Meanwhile, when some special values are given to the four internal parameters, the new criteria have the same expression as some classical failure criteria, such as ChangChang criteria, Hashin criteria, Linde criteria, and Hou criteria in two dimensional case, which are used frequently in the research of damage process for the composite structures.

In general, the four internal parameters should be chosen by experiments. One example that chooses proper values for the parameters is given, which also validates that there is no one and only set of value for the parameters in any criterion.

\section{Conflict of Interests}

The authors declare that there is no conflict of interests regarding the publication of this paper.

\section{Acknowledgment}

This work is financially supported by the National Natural Science Foundation of China under Grant 11072202.

\section{References}

[1] S. Agrawal, Kalyan Kumar Singh, and P. K. Sarkar, "Impact damage on fibre-reinforced polymer matrix composite-a review," Journal of Composite Materials, vol. 48, no. 3, pp. 317-332, 2014.

[2] Y. X. Zhang and C. H. Yang, "Recent developments in finite element analysis for laminated composite plates," Composite Structures, vol. 88, no. 1, pp. 147-157, 2009.

[3] A. C. Orifici, I. Herszberg, and R. S. Thomson, "Review of methodologies for composite material modelling incorporating failure," Composite Structures, vol. 86, no. 1-3, pp. 194-210, 2008.

[4] P. F. Liu and J. Y. Zheng, "Recent developments on damage modeling and finite element analysis for composite laminates: a review," Materials and Design, vol. 31, no. 8, pp. 3825-3834, 2010.

[5] J. G. Michopoulos, "On the reducibility of failure theories for composite materials," Composite Structures, vol. 86, no. 1-3, pp. 165-176, 2008.

[6] M. J. Hinton and P. D. Soden, "Failure criteria for composite laminates," Composites Science and Technology, vol. 58, no. 7, pp. 1001-1010, 1998.

[7] P. D. Soden, M. J. Hinton, and A. S. Kaddour, "Lamina properties and lay-up configurations and loanding conditions of a range fiber reinforced composite laminates," Composites Science and Technology, vol. 58, pp. 1137-1150, 1998.

[8] P. D. Soden, M. J. Hinton, and A. S. Kaddour, "A comparison of the predictive capabilities of current failure theories for composite laminates," Composites Science and Technology, vol. 58, no. 7, pp. 1225-1254, 1998.

[9] M. J. Hinton, P. D. Soden, and A. S. Kaddour, "Evaluation of failure prediction in composite laminates: background to Part B of the exercise," Composites Science and Technology, vol. 62, pp. 1481-1488, 2002.

[10] M. J. Hinton, A. S. Kaddour, and P. D. Soden, "A further assessment of the predictive capabilities of current failure theories for composite laminates: comparison with experimental evidence," Composites Science and Technology, vol. 64, no. 3-4, pp. 549-588, 2004.

[11] A. S. Kaddour, M. J. Hinton, and P. D. Soden, "A comparison of the predictive capabilities of current failure theories for composite laminates: additional contributions," Composites Science and Technology, vol. 64, no. 3-4, pp. 449-476, 2004.

[12] O. Hoffman, "The brittle strength of orthotropic material," Journal of Composite Materials, vol. 9, no. 2, pp. 200-205, 1975.

[13] R. Narayanaswami and H. M. Adelman, "Evaluation of the tensor polynominal and Hoffman strength theories for composite materials," Journal of Composite Materials, vol. 11, no. 4, pp. 366377, 1977.

[14] S. W. Tsai and E. M. Wu, "A general theory for anisotropic materials," Journal of Composite Materials, vol. 5, pp. 58-80, 1971. 
[15] Z. Haszin, "Failure criteria for unidirectional fiber composites," Journal of Applied Mechanics, Transactions ASME, vol. 47, no. 2, pp. 329-334, 1980.

[16] J. P. Hou, N. Petrinic, C. Ruiz, and S. R. Hallett, "Prediction of impact damage in composite plates," Composites Science and Technology, vol. 60, no. 2, pp. 273-281, 2000.

[17] F.-K. Chang and K.-Y. Chang, "A progressive damage model for laminated composites containing stress concentrations," Journal of Composite Materials, vol. 21, no. 9, pp. 834-855, 1987.

[18] K.-Y. Chang, S. Liu, and F.-K. Chang, "Damage tolerance of laminated composites containing an open hole and subjected to tensile loadings," Journal of Composite Materials, vol. 25, no. 3, pp. 274-301, 1991.

[19] P. Maimi, J. A. Mayugo, and P. P. Camanho, "A threedimensional damage model for transversely isotropic composite laminates," Journal of Composite Materials, vol. 42, no. 25, pp. 2717-2745, 2008.

[20] P. Maimí, P. P. Camanho, J. A. Mayugo, and C. G. Dávila, “A continuum damage model for composite laminates-part Iconstitutive model," Mechanics of Materials, vol. 39, no. 10, pp. 897-908, 2007.

[21] P. Linde, J. Pleitner, H. D. Boer, and C. Carmore, "Modelling and simulation of fiber metal laminates," in Proceedings of the ABAQUS User's Conference, pp. 421-439, Boston, Mass, USA, 2004.

[22] C. Santiuste, S. Sánchez-Sáez, and E. Barbero, "A comparison of progressive failure of composite laminated beams," Composite Structures, vol. 92, pp. 2406-2414, 2010.

[23] T. Anderson, Fracture Mechanics-Fundamentals and Applications, 2nd edition, 1995.

[24] I. M. Daniel and O. Ishai, Engineering Mechanics of Composite Materials, Oxford University, 1994.

[25] S. T. Pinho, Modelling failure of laminated composites using physically based failure models [Ph.D. thesis], Imperial College, 2005.

[26] M. 1. Ribeiro, Volnei Tita, and D. Vandepitte, "A new damage model for composite laminates," Composite Structures, vol. 94, pp. 635-642, 2012.

[27] R. M. Richard and J. R. Blacklock, "Finite element analysis of inelastic structures," AIAA Journal, vol. 7, pp. 432-438, 1969.

[28] A. Puck and H. Schürmann, "Failure analysis of FRP laminates by means of physically based phenomenological models," Composites Science and Technology, vol. 62, no. 12-13, pp. 1633-1662, 2002.

[29] P. D. Soden, M. J. Hinton, and A. S. Kaddour, "Biaxial test results for strength and deformation of a range of E-glass and carbon fibre reinforced composite laminates: failure exercise benchmark data," Composites Science and Technology, vol. 62, no. 12-13, pp. 1489-1514, 2002. 

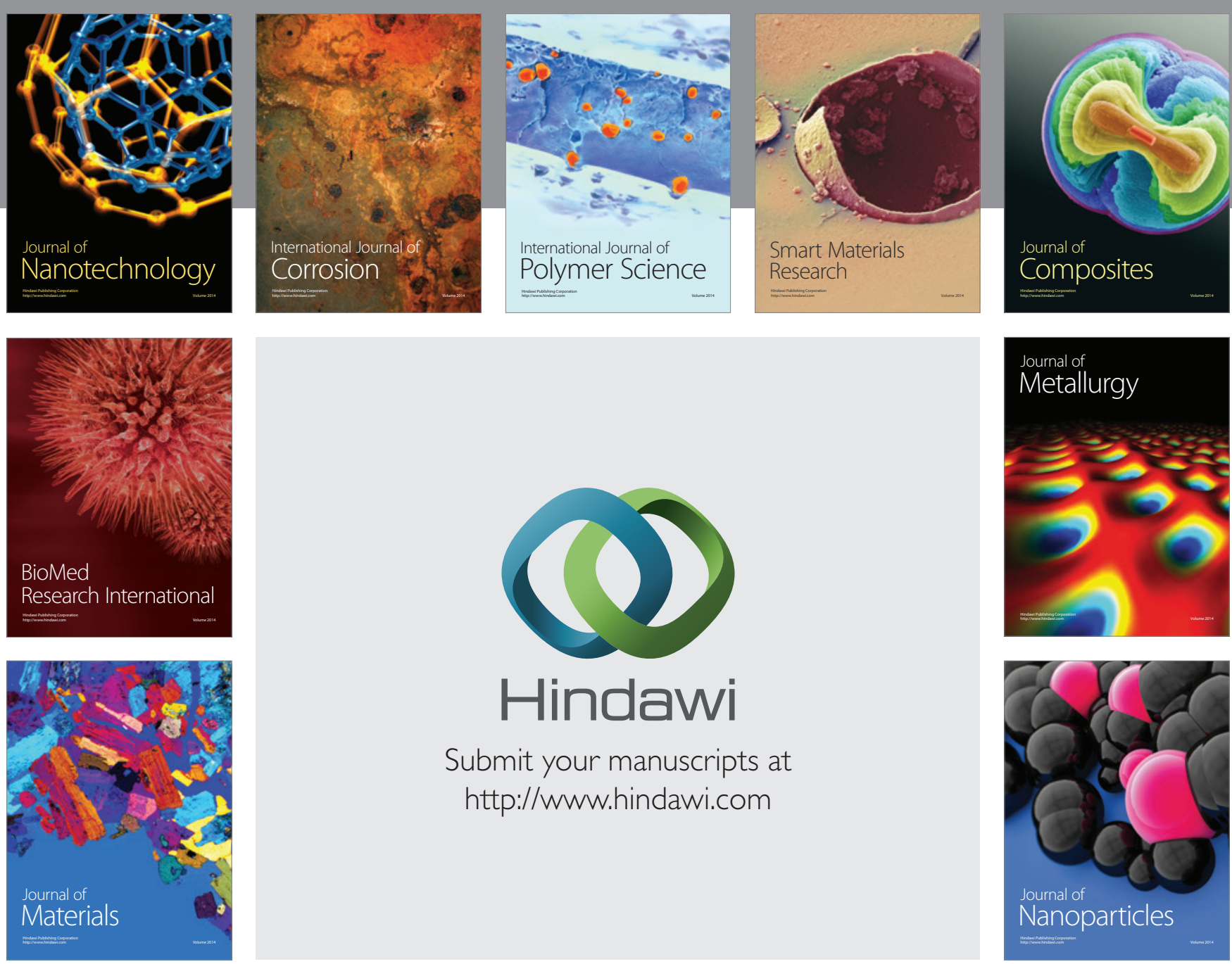

Submit your manuscripts at http://www.hindawi.com
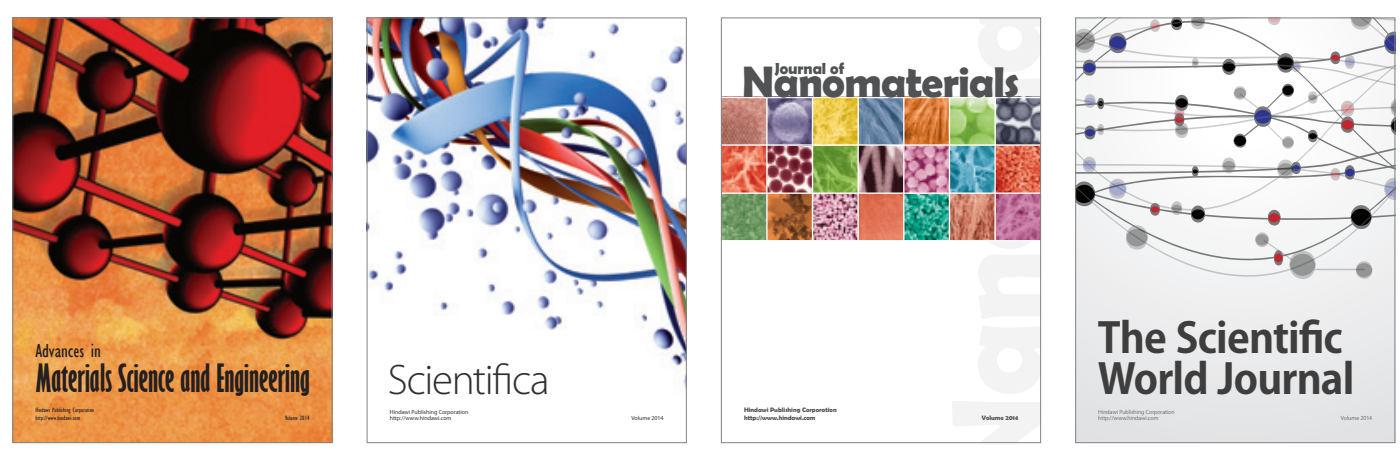

\section{The Scientific World Journal}
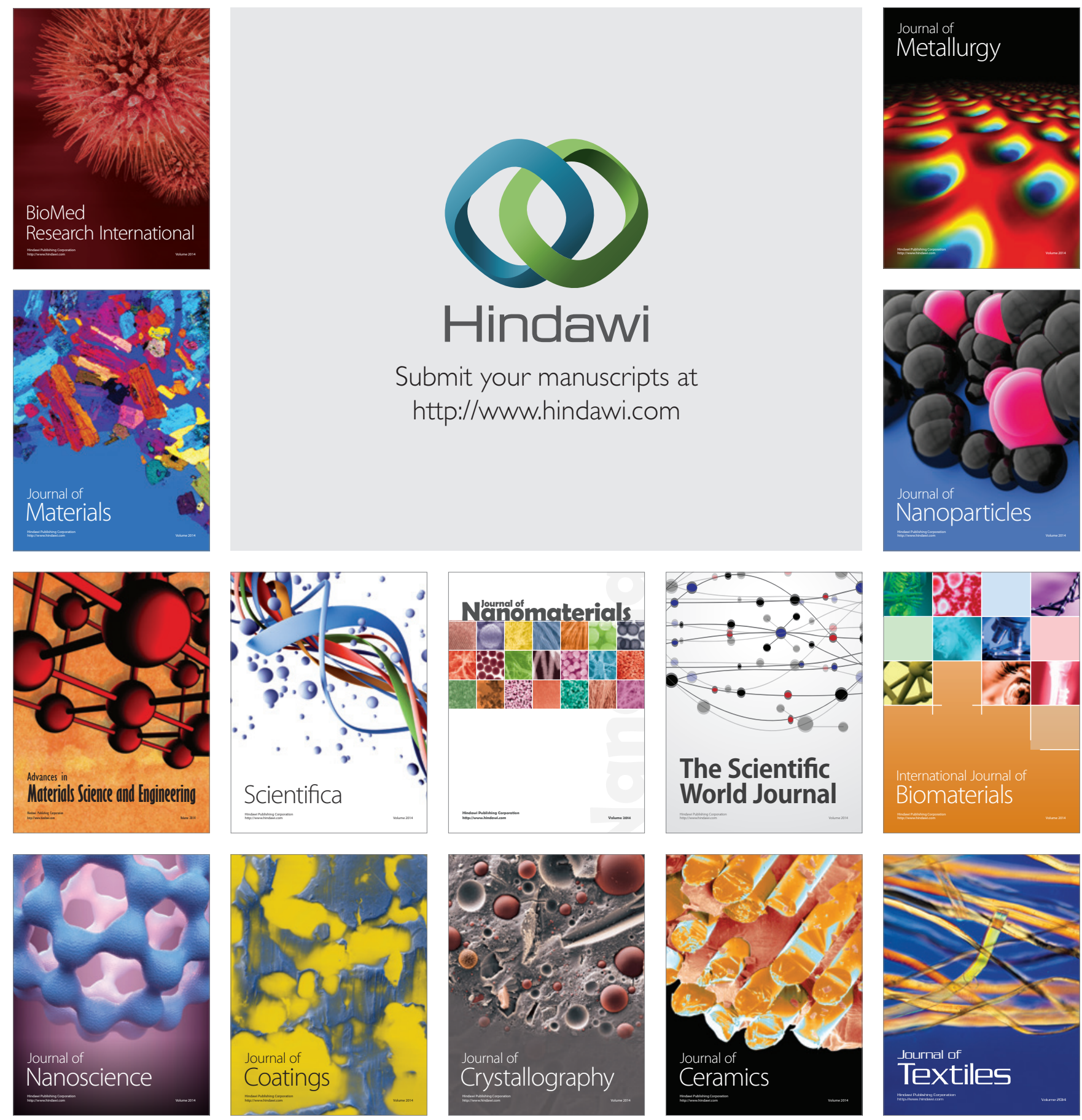